www.jmscr.igmpublication.org

Index Copernicus Value: 79.54

ISSN (e)-2347-176x ISSN (p) 2455-0450

crossrefDOI: https://dx.doi.org/10.18535/jmscr/v7i3.141

\title{
Veress Needle Technique -A Gold Standard Method for Attaining Pneumoperitoneum in Laparoscopic Appendicectomy- A Comparison with Open Technique
}

\author{
Authors \\ Manjunath $\mathbf{H}^{\mathbf{1}}$, Reny Jayaprakas ${ }^{2^{*}}$
}

${ }^{1}$ Associate Prof, Dept of General Surgery, AL- Azhar Medical College and Hospital, Thodupuzha, Kerala

${ }^{2}$ Assistant Prof, Dept of General Surgery, AL- Azhar Medical College and Hospital, Thodupuzha, Kerala

*Corresponding Author

Reny Jayaprakas

Email: drrenysurgeon@gmail.com

\begin{abstract}
Aim: To compare outcome and complications in open technique and closed veress needle technique in laparoscopic appendicectomy.

Methods: A randomized study conducted in 90 patients undergoing laparoscopic appendicectomy in Al Azhar Medical College and Hospital from February 2018 to February 2019.Patients fulfilling the Inclusion-Exclusion criteria were included in the study. Group A constituted 45 patients who underwent Open (Hasson) technique while Group B also contains same number of patients who were taken up for Closed (Veress) technique. Open technique was performed through stab incision and then dissecting the fascia for gaining acess to the abdomen by inserting the trochar, while the closed technique involves the direct insertion of veress needle into the abdominal cavity for pneuoperitoneum creation and then trocar placement. The parameters used for comparison were access time, gas leak, visceral injury, vascular injury, need for conversion, port site haematoma /infection/hernia. Cases were assesed on $1^{\text {st }}$ postoperative day, then followed up at 1 week, 2 months, 6months.

Results: Out of 90 patients, 60 males and 30 females in the age group of 20 to 50 years were included in the study. Mean acess time for pneumoperitoneum was $4+/-1$ minute in open technique versus $3+/-1$ in open technique. Gas leak was observed in 10 patients in group $A$ and 2 patients in Group $B$. Pneumoperitoneum was attained in all cases. There was no case of visceral/vascular injury or conversion to open technique. 3 patients had postoperative haematoma in Group A.5 patients had port site infections in Group A. Post operative hernia was not detected in 6 months postoperative follow up period.

Conclusion: Both open and closed method to gain acess into peritoneal cavity are safe but Veress needle method has the advantage of quicker access time, fewer complications in comparison to open technique.

Keywords: Pneumoperitoneum, Open Technique, Closed Veress needle Technique, Laparoscopic Appendicectomy.
\end{abstract}

\section{Introduction}

Access into abdomen is the one challenge of laparoscopy that is particular to the insertion of surgical instruments through small incisions. Laparoscopic approach is the method of choice for treating benign abdominal diseases requiring 
surgery. However, laparoscopic procedures are not risk free. Complications of laparoscopic surgery are rare and commonly occur while attempting to gain access into the peritoneal cavity ${ }^{1}$. Creating pneumoperitoneum is the first and most critical step of laparoscopic surgery as it can cause injuries to gastrointestinal tract and major blood vessels and atleast 50\% of these complications occur before starting surgery ${ }^{2}$.The number of vascular injuries in laparoscopic surgery is 2 in 10000 procedures and a serious complication associated with mortality occurs in 3.3 per $1,00,000$ cases $^{3}$. There are 2 methods for creating pneumoperitoneum- the closed technique

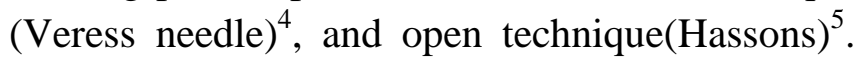
There are many studies regarding how pneumoperitoneum should be created but the decision ultimately rests on the surgeons experience and preference.

\section{Materials and Methods}

This randomized comparative study was conducted from February 2018 to February 2019 in department of general surgery, Al Azhar Medical College, Kerala. A total of 90 patients in the age group of 20 to 50 years were included in the study.

Inclusion Criteria: Patients with symptoms of acute appendicitis without any contraindications for laparoscopic surgery.

Exclusion Criteria: Contraindications for laparoscopic procedure like respiratory compromise, malignancy, or other comorbidities were excluded from the study. Cases with complications like appendicular mass or abcess were excluded.

For all the patients the diagnosis was confirmed by detailed history and examination followed ultrasound anbdomen. CT Abdomen was taken in certain cases.

Group A contained 45 patients who were randomized for open technique and Group B contained 45 patients who underwent closed technique. Open technique was performed through stab incision and then dissecting the fascia for gaining access to the abdomen by inserting the trocar, while the closed technique involves the direct insertion of veress needle into the abdominal cavity for pneuoperitoneum creationu and then trocar placement. The parameters used for comparison were acess time, gas leak, visceral injury, vascular injury, need for conversion, port site haematoma /infection/hernia .Cases were assesed on $1^{\text {st }}$ postoperative day, then followed up at 1 week, 2 months,6months. Data thus collected was tabulated and analysed using appropriate statistical technique.

\section{Result}

Out of 90 patients 60 were male and 30 female. Age group ranged from 20-50 years with mean age of 40 years. The mean acess time needed for creating pneumoperitoneum was $4+/-1$ minute in open technique hand $3+/-1$ minute in closed technique (Table 1 ). Gas leak was observed in 10 cases in Group A and 2 cases in Group B (TABLE 2). Pneumoperitoneum was obtained in all the cases. There were no cases of visceral injury while inserting trocar. No vascular injury occurred in any of the patients. None of the cases were converted into open appendicectomy. Postoperative complications were as follows- 3 cases in Group A had umlical port site haematoma, 5 cases in Group A had surgical site infection at umbilical port. No complications noted in Group B. None of the cases had umbilical hernia postoperatively during the 6 month follow up period.

Table 1: comparison of access time in both groups

\begin{tabular}{|l|c|c|c|}
\hline & $\begin{array}{c}\text { Open technique- } \\
\text { group A }\end{array}$ & $\begin{array}{c}\text { Closed technique- } \\
\text { group B }\end{array}$ & $\begin{array}{c}\mathrm{P} \\
\text { value }\end{array}$ \\
\hline $\begin{array}{l}\text { Access time } \\
\text { (minutes) }\end{array}$ & $4 \pm 1$ & $3 \pm 1$ & 0 \\
\hline
\end{tabular}

Table 2 Comparison of gas leak

\begin{tabular}{|l|c|c|c|}
\hline & $\begin{array}{c}\text { Open } \\
\text { technique }\end{array}$ & $\begin{array}{c}\text { Closed } \\
\text { technique }\end{array}$ & $\begin{array}{c}\text { P } \\
\text { value }\end{array}$ \\
\hline $\begin{array}{l}\text { Cases with gas } \\
\text { leak }\end{array}$ & 10 & 2 & 0.316 \\
\hline
\end{tabular}


Table 3 Comparison of port site complications

\begin{tabular}{|l|c|c|c|}
\hline & $\begin{array}{c}\text { Open } \\
\text { technique }\end{array}$ & $\begin{array}{c}\text { Closed } \\
\text { technique }\end{array}$ & $\begin{array}{c}\text { P } \\
\text { value }\end{array}$ \\
\hline Port site hematoma & 3 & 0 & 0.154 \\
\hline Port site infection & 5 & 0 & 0.042 \\
\hline $\begin{array}{l}\text { Umbilical port site } \\
\text { hernia }\end{array}$ & 0 & 0 & 0 \\
\hline
\end{tabular}

\section{Discussion}

Over the last two decades rapid advancements have made laparoscopic surgery a well established procedure for both diagnostic and therapeutic purpose. Laparoscopic approach is the method of choice for treating benign abdominal diseases requiring surgery. To establish pneumoperitoneum, access to the peritoneal cavity can be gained through minilaparotomy and insertion of laparoscopic trocar. Alternatively an optical trocar can be blindly inserted into the peritoneal cavity or veress needle may $b$ se inserted through abdominal midline.

In our study access time for pneumoperitoneum creation and insertion of camera port was lesser in closed technique, in Scandinavian journal the access time was214- 300 seconds ${ }^{6}$, compared to other studies 240- 300 seconds for open access $6,7,8$. Bogotta reported 130 seconds for closed pneumoperitoneum ${ }^{9}$.Byron et al. also reported 2.2 mins ${ }^{10}$. Argoli et al. also reported longer access time with veress needle ${ }^{11}$. In a study by Somro et al. the time used for creation of pneumoperitoneum was 5 mins by closed and 8 minutes by open technique ${ }^{12}$.

In our study 10 patients in open technique and 2 patients each in closed technique developed gas leak. The number of entry related complications with open technique was significantly higher than closed technique.

Meta-analysis failed to reveal any safety advantage of open versus closed technique of entry in terms of both visceral and vascular injury. It must be noted that the included randomised control trials had insufficient power to effectively demonstrate an advantage ${ }^{13}$.

In our study, open technique $3(6.66 \%)$ developed port site hematoma, which was not noted in closed technique. Our results are comparable to other studies like Shindholimath et al. $-6.3 \%$, Colizzi et al. $2 \%^{14,15}$. Umblical port site infection was noted in $5(11.11 \%)$ of open technique cases. Superficial skin infection is more common and has been reported by studies 16 .

No port site hernia was reported in our study, but in other study it was $1.7 \%{ }^{17}$.

\section{Conclusion}

Both open and closed technique for gaining access into peritoneal cavity are safe. But veress needle is quicker with fewer associated complications. As per our study veress needle technique should be considered as gold standard method for attaining pneumoperitoneum.

\section{References}

1. R. Varma and J.K. Gupta, "Laparoscopic entry techniques: clinical guideline, national survey, and medicolegal ramifications, "Surgical Endoscopy and Other Interventional Techniques, vol.22, no.12,pp.2686-2697,2008.

2. S. Krishnakumar and P.Tambe, "Entry complications in laparoscopic surgery," Journal of Gynaecological Endoscopy and Surgery, vol1,no 1,p.p. 4-11,2009.

3. D.C. Wherry, M.R. Marohn, M.P. Malanoski, S.P.Hetz, and N.M.Rieh,"An external audit of laparoscopic cholecystectomy in state performed in medical treatment facilities of the Department of defense, "Annals of surgery, Vol 224,no2,pp145 - 154,1996.

4. D.N.Patel, M. N. Parikh, M.S Nanavati and M.J. Jusssawalla, "Complication of Laproscopy," Asia-Oceania Journal of Obstetrics and Gynaecology, vol. 11, no.1, pp 87-91, 1985.

5. H. M Hasson, "A modified instrument and method for laproscopy," American Journal of Obstetrics and Gynecology, Vol. 110, no.6, pp. 886-887, 1971.

6. Moberg AC, Petersson U, Montgomary A. An open access technique to create 
pneumoperitoneum in laparoscopic surgery. Scand J Surg 2007: 297-300

7. Bernik T R, Trocciola SM, Mayer DA. Ballon blunt-tip trocar for laparoscopic cholecystectomy: improvement over the traditional Hasson and Veress needle methods. J Laparoendosc Adv Surg Tech 2001; 11:73-78.

8. Pawanindra L, Sharma R, Chander J, Ramteke VK. A technique for open trocar placement in laparoscopic surgery using the umbilical cicatrix tube. Surg Endosc 2002; 16:1366-70

9. Borgatta L, Gruss L, Barad D, Kaali SG. Direct trocar insertion vs Veress needle use for laparoscopic sterilization. J Reprod Med 1990; 35: 891-94.

10. Byron JW, Markenson G, Miyazawa K. A randomized comparison of Veress needle and direct trocar insertion for laparoscopy. Surg Gynecol Obstet 1993; 177:259-62.

11. Angioli R, Terranova C, Nardone C., Cafa Damiani P. A comparison of three different entry techniques in gynecological laparoscopic surgery: A randomized prospective trial. European Journal of Obstetrics Gynecology and Reproductive Biology 2013;171(2): 339-42

12. Soomro AH. Creation of pneumoperitoneum by a new technique prior to laparoscopic procedure. J Liaquat Uni Med Health Sci 2004; 3:18-21

13. Ahmad G, Duffy JMN, Phillips K. Laparoscopic entry techniques. Cochrane Database of Systematic Reviews, no. 16, Article ID CD006583, 2008.

14. Den Hoed PT, Boelhouwer RU, Veen HF, Hop WC. Infections and bacteriological data after laparoscopic and open gallbladder surgery. J Hosp Infect 1998;39:27-37

15. Shindholimath VV, Seenu V, Parshad R, Chaudhry R. Factors influencing wound infection following laparoscopic cholecystectomy. Trop Gastroenterol. 2003;24:90-92

16. Richards C, Edwards J, Culver D, Emori TG. The National nosocomial infections surveillance (NNIS) system, centers for disease control and prevention. Does using a laparoscopic approach to cholecystectomy decrease the risk of surgical site infection? Ann Surg. 2003;237:358- 62 .

17. Mark B D. Port-site hernia following laparoscopic cholecystectomy. Journal of the Society of Laparoendoscopic Surgeons 2010; 14(4):490-97. 